\title{
Óleo essencial de Lippia sidoides nativas de Minas Gerais: Composição, estruturas secretoras e atividade antibacteriana ${ }^{1}$
}

\author{
Essential oil of Lippia sidoides native to Minas Gerais: Composition, secretory \\ structures and antibacterial activity
}

\author{
Luiz Gustavo de Lima Guimarães ${ }^{2 *}$, Maria das Graças Cardoso ${ }^{3}$, Ricardo Magela de Souza ${ }^{4}$, Ana Beatriz \\ Zacaroni $^{5}$ e Gil Rodrigues dos Santos ${ }^{6}$
}

\begin{abstract}
RESUMO - Tendo em vista as diversas atividades biológicas apresentadas pelos óleos essenciais e o potencial antibacteriano do óleo essencial de Lippia sidoides Cham., objetivou-se, com este trabalho, caracterizar o óleo essencial desta espécie coletada na região sul do estado de Minas Gerais-Brasil, bem como identificar as suas estruturas secretoras e avaliar sua atividade antimicrobiana sobre as fitobactérias Clavibacter michiganensis subsp. Michiganensis, Xanthomonas vesicatoria e Pseudomonas syringae pv. tomato. As plantas foram coletadas no município de Itumirim e os óleos essenciais de suas folhas, extraídos por hidrodestilação, utilizando-se um aparelho de Clevenger modificado. O óleo essencial apresentou como constituintes majoritários o carvacrol $(26,44 \%)$ e o 1,8-cineol $(22,63 \%)$. Nas superfícies foliares de $L$. sidoides foram encontrados tricomas glandulares e não glandulares. Entre os tricomas glandulares, encontram-se tricomas capitados do tipo I e tricomas peltados. Foram reveladas a presença de substâncias lipídicas e terpênicas no interior das células das cabeças dos tricomas peltados e capitados. apresentando as seguintes CMI: 7,81 $\mu \mathrm{g} \mathrm{mL}^{-1}$ sobre $C$. michiganensis, $3,9 \mu \mathrm{g} \mathrm{mL}^{-1}$ sobre $P$. syringae e $15,62 \mu \mathrm{g} \mathrm{mL}^{-1}$ sobre $X$. vesicatoria. $\mathrm{O}$ carvacrol, seu constituinte majoritário, apresentou valores de CMI igual a 3,9 $\mu \mathrm{g} \mathrm{mL}^{-1}$ sobre todas as três bactérias estudadas. Ambos demonstraram a capacidade de inibir o crescimento de bactérias Gram-positivas e Gram-negativas.
\end{abstract}

Palavras-chave: Carvacrol. Clavibacter michiganensis. Xanthomonas vesicatoria. Pseudomonas syringae.

\begin{abstract}
Given the diverse biological activities presented by essential oils, and the antibacterial potential of the essential oil of Lippia sidoides Cham, the objective of this work was to characterise the essential oil of this species, collected in the southern part of the state of Minas Gerais, Brazil, as well as to identify its secretory structures and evaluate its antimicrobial activity on the phytobacteria, Clavibacter michiganensis subsp. Michiganensis, Xanthomonas vesicatoria and Pseudomonas syringae pv. tomato. Plants were collected in the town of Itumirim, and the essential oils of the leaves extracted by hydrodistillation using a modified Clevenger apparatus. The essential oil presented carvacrol (26.44\%) and 1.8-cineole (22.63\%) as major constituents. On the leaf surface of L. sidoides both glandular and nonglandular trichomes were found. Among the glandular trichomes are peltate trichomes and type I capitate trichomes. The presence of lipidic and terpenic substances within the head cells of both the peltate and capitate trichomes was found. The essential oil of $L$. sidoides was able to inhibit the growth of all the microorganisms studied, showing the following MIC: $7.81 \mu \mathrm{g} \mathrm{mL}^{-1}$ for C. michiganensis, $3.9 \mu \mathrm{g} \mathrm{mL}^{-1}$ for P. syringae and $15.62 \mu \mathrm{g} \mathrm{mL}^{-1}$ for X. vesicatoria. Carvacrol, the major constituent, showed MIC values equal to $3.9 \mu \mathrm{g} \mathrm{mL}^{-1}$ for all three bacteria studied. Both exhibited the ability to inhibit the growth of gram-positive and gram-negative bacteria.
\end{abstract}

Key words: Carvacrol. Clavibacter michiganensis. Xanthomonas vesicatoria. Pseudomonas syringae.

\footnotetext{
*Autor correspondência

'Recebido para publicação em 06/09/2012; aprovado em 24/08/2013

Parte da Tese de Doutorado, do primeiro autor, apresentada ao programa de Pós-Graduação em Agroquímica da Universidade Federal de Lavras/UFLA ${ }^{2}$ Departamento de Ciências Naturais, Universidade Federal de São João Del Rei, São João Del Rei-MG, Brasil, 36.301-160, lguimaraes@ufsj.edu.br ${ }^{3}$ Departamento de Química, Universidade Federal de Lavras, Lavras-MG, Brasil, 37.200-000, mcardoso@ dqi.ufla.br ${ }^{4}$ Departamento de Fitopatologia, Universidade Federal de Lavras, Lavras-MG, Brasil, 37.200-000, rmagelas @ ufla.br

${ }^{5}$ Programa de Pós-Graduação em Fitopatologia, Universidade Federal de Lavras, Lavras-MG, Brasil, 37.200-000, ana.zacaroni@ hotmail.com

${ }^{6}$ Programa de Pós-Graduação em Produção Vegetal/Universidade Federal do Tocantins, Gurupi-TO, Brasil, gilrsan@ uft.edu.br
} 


\section{INTRODUÇÃO}

Em geral, as atividades biológicas dos óleos essenciais são bem documentadas, principalmente no que diz respeito às atividades microbiológicas. Vários estudos têm sido realizados avaliando suas atividades frente a diversos tipos de microrganismos. Como deterioradores de alimentos, patógenos e fitopatógenos, revelando o potencial de determinados óleos essenciais no controle de tais microrganismos (BAKKALI et al., 2008).

A espécie Lippia sidoides Cham. (Verbenaceae), conhecida popularmente como "alecrim pimenta", é uma planta aromática encontrada na região de Caatinga do Nordeste brasileiro (CAVALCANTI et al., 2010) e tem mostrado diversas atividades biológicas, o que a tem tornado uma fonte potencial de compostos biologicamente ativos. Estudos recentes têm relatado diversas propriedades biológicas para seu óleo essencial, como as inseticidas, contra Tenebrio molitor (LIMA et al., 2011), sobre larvas de Aedes aegypti L. (CAVALCANTI et al., 2004) e antibacteriana perante as bactérias de alimentos Staphylococcus aureus, Pseudomonas aeruginosa e Escherichia coli (BERTINI et al., 2005) e também contra bactérias do gênero Streptococcus e o fungo Candida albicans (BOTELHO et al., 2007).

Diversos gêneros, espécies, subespécies e patovares de bactérias fitopatogênicas são responsáveis por doenças em solanáceas, assumindo um papel de importância na cultura do tomateiro, uma vez que podem limitar sua produção. Entre as principais causadoras de doenças na cultura encontram-se a Clavibacter michiganensis subsp. Michiganensis (Gram-positiva), causadora do cancrobacteriano, Xanthomonas vesicatoria (Gram-negativa), causadora da mancha-bacteriana, e a Pseudomonas syringae pv. Tomato (Gram-negativa), causadora da pintabacteriana (KIMATI et al., 2005).

A síntese e o acúmulo dos óleos essenciais estão geralmente associados com a presença de estruturas secretoras especializadas. Segundo Svoboda e Greenaway (2003), essas estruturas são divididas em estruturas de secreção internas (cavidades e os canais secretores) e externas (tricomas glandulares). O conhecimento sobre a anatomia foliar de plantas medicinais é uma valiosa contribuição para a correta identificação das espécies estudadas, sendo estudos dessa natureza essenciais para o manejo e conservação das espécies nativas medicinais bem como para a compreensão das relações dessas espécies com o ambiente (NASCIMENTO-SILVA; PAIVA, 2007).

Considerando a importância da espécie $L$. sidoides como planta medicinal, utilizada no nordeste brasileiro, e o potencial de seu óleo essencial como agente antimicrobiano, este trabalho teve como objetivo avaliar a composição química do óleo essencial de plantas de L. sidoides nativas da região sul do estado de Minas Gerais-Brasil, bem como verificar a morfologia e caracterizar por meio de testes histoquímicos as suas estruturas secretoras e avaliar sua atividade antimicrobiana sobre as fitobactérias Clavibacter michiganensis subsp. Michiganensis, Xanthomonas vesicatoria e Pseudomonas syringae pv. tomato.

\section{MATERIAL E MÉTODOS}

\section{Obtenção do material vegetal}

As folhas de L. sidoides (Verbenaceae) foram coletadas no mês de outubro, no período da manhã, no município de Itumirim, Minas Gerais-Brasil. O material coletado foi encaminhado para o Laboratório de Química Orgânica do Departamento de Química - UFLA, para a extração dos óleos essenciais. A espécie foi devidamente identificada pela Dr ${ }^{\mathrm{a}}$. Mariana Esteves Mansanares, uma exsicata da mesma encontra-se registrada no Herbário ESAL, localizado no Departamento de Biologia da UFLA, com o número de registro 0194.

\section{Extração do óleo essencial}

Para extração dos óleos essenciais, empregou-se a metodologia de hidrodestilação, utilizando-se um aparelho de Clevenger modificado, sendo o processo de extração realizado em um período de 2 horas. O hidrolato coletado foi centrifugado em centrífuga de cruzeta horizontal a 900 g por cinco minutos. Posteriormente, o óleo essencial foi acondicionado em frasco de vidro âmbar a $4{ }^{\circ} \mathrm{C}$ e ao abrigo da luz. Paralelamente às extrações, realizou-se o teste de umidade, de acordo com o método oficial da "American Oil Chemists' Society" (AOCS), adaptado por Pimentel et al. (2006). O rendimento do óleo essencial foi calculado e expresso em peso de óleo por peso de folhas com base livre de umidade (BLU).

\section{Análises cromatográficas dos óleos essenciais}

As análises qualitativas dos óleos essenciais foram realizadas por cromatografia em fase gasosa acoplada à espectrometria de massa (CG-EM). O cromatógrafo utilizado foi o modelo Shimadzu G-17A equipado com detector seletivo de massa modelo QP5050A. O equipamento foi operado nas seguintes condições: coluna capilar de $30 \mathrm{~m}$ x 0,25 mm x 0,25 DI com fase ligada DB-5MS (Folsom, CA, USA); temperatura da fonte de íons de $280{ }^{\circ} \mathrm{C}$; programação da coluna com temperatura inicial de $50{ }^{\circ} \mathrm{C}$ por $2 \mathrm{~min}$, com um aumento de $4{ }^{\circ} \mathrm{C} / \mathrm{min}$, até $200{ }^{\circ} \mathrm{C}$, depois $10{ }^{\circ} \mathrm{C} / \mathrm{min}$ até $300{ }^{\circ} \mathrm{C}$, 
finalizando com uma temperatura de $300{ }^{\circ} \mathrm{C}$ por $10 \mathrm{~min}$;

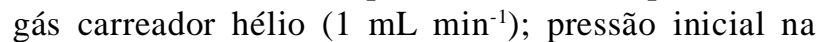
coluna de 100,2 kPa; taxa de split 1:83 e 0,5 $\mu \mathrm{L}$ de óleo essencial injetado $(1: 100(\mathrm{~m} / \mathrm{v})$ em diclorometano). Para o espectrômetro de massas (EM), foram utilizadas as seguintes condições: energia de impacto de 70 eV; velocidade de decomposição 1000; intervalo de decomposição de 0,50; e fragmentos de 40 Da e 550 Da decompostos. Foi injetada, nas mesmas condições da amostra, uma série de padrões de hidrocarbonetos lineares $\left(\mathrm{C}_{9} \mathrm{H}_{20} \ldots \mathrm{C}_{26} \mathrm{H}_{54}\right)$. Os espectros obtidos foram comparados com o banco de dados da biblioteca Wiley 229 e o índice de retenção, calculado para cada constituinte, foi comparado com o valor tabelado, de acordo com Adams (2007).

As análises quantitativas foram feitas utilizando um cromatógrafo gasoso equipado com um detector de ionização de chamas (DIC), utilizando-se um aparelho Shimadzu CG - 17A, nas seguintes condições experimentais: coluna capilar de sílica fundida $(30 \mathrm{~m}$ x 0,25 mm) com fase ligada DB5 $(0,25 \mu \mathrm{m}$ de espessura de filme); temperatura do injetor: $250{ }^{\circ} \mathrm{C}$; temperatura do DIC: $280{ }^{\circ} \mathrm{C}$; programação da coluna: temperatura inicial de $60{ }^{\circ} \mathrm{C}$ por dois minutos, seguida por uma taxa de aquecimento de $4{ }^{\circ} \mathrm{C} / \mathrm{min}$ até $200{ }^{\circ} \mathrm{C}$, em seguida, passando para uma taxa de aquecimento de $10{ }^{\circ} \mathrm{C} / \mathrm{min}$ até $300^{\circ} \mathrm{C}$, permanecendo nessa temperatura por $10 \mathrm{~min}$.; gás de arraste nitrogênio $\left(2,2 \mathrm{~mL} \mathrm{~min}^{-1}\right)$; taxa de split 1:20; pressão na coluna de $115 \mathrm{kPa}$ e volume injetado de $1 \mu \mathrm{L}$ de óleo essencial injetado (1:100 (m/v) em hexano).

\section{Análises morfológicas}

As análises ultraestruturais foram feitas por meio de microscopia eletrônica de varredura (MEV), utilizando um microscópio modelo LEO EVO 40. Foram utilizadas folhas adultas, lavadas em água corrente, e cortadas em dimensões aproximadas de $0,5 \times 0,5 \mathrm{~cm}$ na região contendo a nervura central. $\mathrm{O}$ material foi imerso em solução fixadora de Karnovsky, pH 7,2, por um período de 24 horas. Em seguida, os fragmentos foram lavados três vezes em tampão cacodilato $0,05 \mathrm{M}$, por 10 minutos. Posteriormente, as secções foram transferidas para uma solução de tetróxido de ósmio $\left(\mathrm{OsO}_{4}\right)$ 1,0\% (m/v) por 1 hora. $\mathrm{O}$ material foi lavado em água destilada por três vezes e desidratado em soluções aquosas de acetona nas concentrações de $25 \%, 50 \%, 75 \%, 90 \%$ e $100 \%$ (v/v). Após a desidratação, as amostras foram levadas para o aparelho de ponto crítico Balzers CPD 030 para substituição da acetona por $\mathrm{CO}_{2}$ e complementação da secagem. As amostras obtidas foram montadas em suportes de alumínio stubs com fita de carbono sobre uma película de papel-alumínio e cobertos com ouro no evaporador Balzers SCD 050, sendo, em seguida, observados por MEV.

\section{Análises histoquímicas}

Folhas frescas foram seccionadas à mão livre com lâmina de aço, transversalmente na região da nervura central. Os cortes foram distribuídos em vidros de relógio contendo Sudan III para a verificação de lipídeos, cutina e suberina e em vidros de relógio contendo o reagente de Nadi para detecção de terpenos. Os cortes corados com Sudan III permaneceram imersos nesse reagente por 15 minutos e, em seguida, foram lavados em água destilada. Os cortes corados com reagente de Nadi ficaram imersos nesse reagente por 60 minutos no escuro e, em seguida, foram lavados em tampão fosfato de sódio $0,1 \mathrm{M} \mathrm{pH} 7,2$ por 5 minutos. Depois de corados, os cortes foram montados em lâminas semipermanentes com água glicerinizada. As observações foram feitas no Microscópio de Luz (Leica DMLS) com câmera fotográfica acoplada (Canon PowerShot S40).

\section{Avaliação da atividade bacteriana in vitro}

As análises das atividades bacterianas do óleo essencial de $L$. sidoides foram realizadas utilizando a metodologia de difusão em cavidade agar (LIMA et al., 2012). Foram utilizados os isolados de Clavibacter michiganensis subsp. Michiganensis, Xanthomonas vesicatoria e Pseudomonas syringae pv. Tomato. As bactérias foram preservadas em ultra freezer e, posteriormente, inoculadas em plantas de tomateiro, para comprovar sua virulência. As folhas e as hastes que apresentaram sintomas foram utilizadas como fonte de inóculo para $X$. vesicatoria, $P$. syringae e $C$. michiganensis, respectivamente, para a realização dos ensaios. Os isolamentos das bactérias foram feitos a partir de materiais vegetais previamente infectados pela técnica de estrias paralelas, utilizando o meio MB1 como meio de cultura. As bactérias foram cultivadas no mesmo meio por 24 horas a $28{ }^{\circ} \mathrm{C}$, antes do preparo do inóculo. As suspensões bacterianas foram ajustadas em espectrofotômetro para $\mathrm{A}_{600}=0,30$, correspondendo aproximadamente a $5 \times 10^{8} \mathrm{UFC}^{-1}$ para $X v$ (LUCAS et al., 2012); $\mathrm{A}_{560}=0,10$, correspondendo aproximadamente a 8

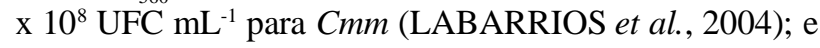
$\mathrm{A}_{540}=0,20$, correspondendo aproximadamente a $5 \times 10^{8}$ UFC $\mathrm{mL}^{-1}$ para Pst (SILVA et al., 2008).

Adicionou-se uma fina camada de meio de cultura MB1 às placas de Petri de $15 \mathrm{~cm}$ de diâmetro e, após a solidificação foram colocadas esferas de vidro previamente esterilizadas sobre ele. Alíquotas das suspensões bacterianas foram adicionadas a $20 \mathrm{~mL}$ de meio (MB1) semi-sólido, de maneira a obter uma 
concentração final de $10^{8} \mathrm{UFC} \mathrm{mL}^{-1}$; em seguida, verteuse o meio semi-sólido contendo a suspensão bacteriana sobre a camada sólida contendo as pérolas de vidro. Após solidificação, as esferas de vidro foram retiradas com pinças estéreis para a formação dos "slots" de 0,4 $\mathrm{mm}$, nos quais foram adicionados $10 \mu \mathrm{L}$ das soluções dos óleos essenciais diluídos em dimetilsulfóxido (DMSO). As soluções foram preparadas em escala logarítmica, nas proporções de $1: 1 ; 1: 2 ; 1: 4 ; 1: 8 ; 1: 16$; $1: 32 ; 1: 64 ; 1: 128$ (óleo essencial/solvente), obtendo-se concentrações de $500 ; 250 ; 125 ; 62,5 ; 31,25 ; 15,62$; 7,$81 ; 3,90\left(\mu \mathrm{L} \mathrm{mL} \mathrm{m}^{-1}\right)$. As placas foram armazenadas em geladeira a $5{ }^{\circ} \mathrm{C}$ por duas horas e, posteriormente, incubadas por 48 horas a $28{ }^{\circ} \mathrm{C}$ em BOD, antes da verificação da presença e medição dos diâmetros dos halos. Além do óleo essencial, tiveram suas atividades bacterianas avaliadas os padrões de 1,8-cineol (99\%, Acrõss) e carvacrol (98\%, Sigma-Aldrich).

As análises foram realizadas em triplicatas, e os tratamentos dispostos de forma inteiramente casualizada. Foi feita a análise de variância seguida pelo teste $\mathrm{F}$ para verificação dos efeitos de tratamentos, a 5\% de probabilidade, sendo utilizada a análise de regressão para avaliar os diâmetros dos halos de inibição do crescimento bacteriano em relação à concentração, sendo utilizado o programa estatístico SISVAR (FERREIRA, 2000).

\section{RESULTADOS E DISCUSSÃO}

O rendimento do óleo essencial, expresso em porcentagem p/p BLU, das plantas de L. sidoides foi de $0,873 \pm 0,23 \%$. A sua constituição química, seguida pelos tempos de retenção, índices de retenção calculados e tabelados e os teores expressos em porcentagem (calculados por normalização de áreas) para cada constituinte encontram-se na Tabela 1.

O óleo essencial de L. sidoides apresentou como constituintes majoritários o carvacrol $(26,44 \%)$ e o 1,8 cineol $(22,63 \%)$. No entanto, grande parte dos estudos realizados com plantas desta mesma espécie nativa da região nordeste do Brasil, demonstram a presença do timol (isômero do carvacrol) como constituinte majoritário de seus óleos essenciais. Como observado por Cavalcanti et al. (2004), que encontraram o timol $(80,8 \%)$ como constituinte majoritário do óleo essencial de plantas desta espécie, coletadas na região nordeste, seguido pelos compostos $\rho$-cimeno $(8,6 \%)$, $(E)$-cariofileno $(5,1 \%), \gamma$-terpineno $(1,6 \%), 1,8$-cineol $(1,3 \%)$ e $\beta$-mirceno $(0,9 \%)$. Estes resultados são similares àqueles encontrados por Botelho et al. (2007), que identificaram como constituintes majoritários do óleo essencial de plantas, também do nordeste, o timol $(56,7 \%)$ e carvacrol $(16,7 \%)$, seguidos pelo $\rho$-cimeno $(7,13 \%)$, timol metil éter $(5,06 \%)$, aromadrendeno $(2,79 \%), 1,8$-cineol $(2,39 \%), \gamma$-elemeno $(2,28 \%), \gamma$ terpineno $(1,42 \%)$, e por Fontenelle et al. (2007) que analisando o óleo essencial dessa espécie coletada no município de Horizonte/Ce, encontraram o timol $(59,65 \%)$ e o $(E)$-cariofileno $(10,60 \%)$ como constituintes majoritários.

Por outro lado, Cavalcanti et al. (2010), estudando o óleo essencial de quatro acessos de $L$. sidoides, coletados em regiões distintas do nordeste brasileiro, encontraram o carvacrol $(46,09 \%)$ seguido pelo $\gamma$-terpineno $(15,49 \%)$ e pelo $\rho$-cimeno $(15,06)$ como constituintes majoritários do óleo essencial das plantas coletadas em regiões distintas do nordeste brasileiro. Lima et al. (2011) encontraram o carvacrol $(31,68 \%)$, $\rho$-cimeno $(19,58 \%), 1,8$-cineol $(9,26 \%)$ e o $\gamma$-terpineno $(9,21 \%)$ como constituintes majoritários do óleo essencial de Lippia sidoides coletadas em Lavras-MG.

Estas variações podem ser justificadas por fatores genéticos, edafoclimáticos e também pelo ciclo vegetativo. De acordo com Gobbo-Neto e Lopes (2007) a produção de metabólitos secundários pode ser influenciada por diversos fatores ambientais, como sazonalidade, índice pluviométrico, ritmo circadiano, altitude, temperatura, ciclo vegetativo da planta, tipo de solo, entre outros. Barros et al. (2009) afirmam que as condições climáticas podem influenciar as atividades enzimáticas em determinada espécie vegetal e, consequentemente, interferir na biossíntese de determinados metabólitos secundários, incluindo compostos terpênicos.

Nas eletromicrografias obtidas por MEV das superfícies foliares de L. sidoides (Figura 1), observou-se a presença de tricomas glandulares e não glandulares em ambas as faces, adaxial e abaxial. Entre os tricomas glandulares, encontram-se tricomas capitados do tipo I e tricomas peltados; ambos foram encontrados nas superfícies adaxial e abaxial. Os tricomas capitados são abundantes em ambas as faces e observa-se maior densidade dessas estruturas na superfície abaxial em relação à adaxial. Os tricomas não glandulares também foram verificados como sendo de dois tipos: o primeiro possui formato cônico, unicelulares e com paredes espessas, apresentando células subsidiárias especiais em torno da base e estando presentes apenas na superfície adaxial; o segundo apresentou-se como tector longo, pluricelular, apresentando maior densidade na superfície abaxial, principalmente sobre as nervuras. 
Tabela 1 - Constituintes químicos do óleo essencial de Lippia sidoides e os seus respectivos teores expressos em porcentagem

\begin{tabular}{|c|c|c|c|c|}
\hline Compostos & TR* & IRC & IRT & Concentração \\
\hline$\alpha$-tujeno & 6,66 & 916 & 931 & $0,97 \pm 0,03$ \\
\hline sabineno & 8,14 & 968 & 976 & $3,57 \pm 0,25$ \\
\hline$\beta$-pineno & 8,24 & 973 & 980 & $0,38 \pm 0,03$ \\
\hline mirceno & 8,75 & 987 & 991 & $1,70 \pm 1,05$ \\
\hline$\alpha$-felandreno & 9,18 & 1006 & 1005 & $1,93 \pm 0,05$ \\
\hline$\alpha$-terpineno & 9,61 & 1016 & 1018 & $1,17 \pm 0,04$ \\
\hline$\rho$-cimeno & 9,88 & 1025 & 1026 & $9,89 \pm 0,31$ \\
\hline limoneno & 10,09 & 1029 & 1031 & $\mathrm{Nd}^{* *}$ \\
\hline 1,8-cineol & 10,13 & 1033 & 1033 & $22,63 \pm 0,40$ \\
\hline$\gamma$-terpineno & 11,14 & 1058 & 1062 & $7,27 \pm 0,11$ \\
\hline terpin-4-ol & 15,51 & 1181 & 1177 & $1,56 \pm 0,03$ \\
\hline$\alpha$-terpineol & 16,00 & 1195 & 1189 & $0,82 \pm 0,04$ \\
\hline verbenona & 16,67 & 1211 & 1204 & $\mathrm{Nd}$ \\
\hline metil-éter-timol & 17,62 & 1229 & 1235 & $1,96 \pm 0,03$ \\
\hline Neral & 17,85 & 1239 & 1240 & $1,56 \pm 0,02$ \\
\hline Timol & 19,73 & 1290 & 1290 & $1,17 \pm 0,10$ \\
\hline carvacrol & 20,10 & 1302 & 1298 & $26,44 \pm 0,65$ \\
\hline timol acetato & 22,48 & 1364 & 1355 & $0,47 \pm 0,07$ \\
\hline$\beta$-elemeno & 23.23 & 1389 & 1391 & $0,43 \pm 0,02$ \\
\hline (E)-cariofileno & 24,17 & 1419 & 1418 & $2,57 \pm 0,07$ \\
\hline$\alpha$-humuleno & 25.29 & 1455 & 1454 & $1,78 \pm 0,05$ \\
\hline dehidro-aromadendrano & 25.47 & 1457 & 1459 & $\mathrm{Nd}$ \\
\hline$\gamma$-muuroleno & 25.95 & 1474 & 1477 & $\mathrm{Nd}$ \\
\hline amorfa-4,7-(11)-dieno & 26.19 & 1480 & 1481 & $0,38 \pm 0,01$ \\
\hline 7-epi-alfa-selineno & 27.26 & 1517 & 1517 & $\mathrm{Nd}$ \\
\hline óxido de cariofileno & 29.42 & 1582 & 1581 & $1,54 \pm 0,05$ \\
\hline
\end{tabular}

*TR = Tempo de retenção $($ minutos), IRC = índice de retenção calculado, IRT = índice de retenção tabelado (Adams 2007). ** Nd = não quantificado (valores $<0,2$ )

As análises histoquímicas do limbo foliar revelaram a presença de substâncias lipídicas no interior das células das cabeças dos tricomas peltados e capitados pelas reações positivas com os reagentes Sudan III e de Nadi, o primeiro evidenciando a presença de substâncias lipídicas e o segundo de substâncias terpênicas (Figura 2). Sendo assim, pode-se inferir que os compostos terpênicos ou parte destes, presentes no óleo essencial desta espécie encontram-se armazenados nos vacúolos ou oleossomos das células presentes na cabeça desses tricomas glandulares. Quanto ao seu mecanismo de secreção, nada se pode afirmar, visto que a MEV não revelou a presença de poros ou de membranas rompidas.
Muitos autores já demonstraram a secreção de óleos essenciais por meio de tricomas em plantas pertencentes à família Verbenacea. Combrick et al. (2007), estudando as estruturas secretoras de Lippia scaberrima, encontraram estruturas semelhantes às descritas no presente trabalho para a espécie L. sidoides. Maggi et al. (2010) demonstraram que a composição do material secretado pelos tricomas glandulares presentes nas folhas de Melittis melissophyllum L. subsp. Melissophyllun varia de acordo com o tipo de tricoma, sendo os tricomas peltados os maiores sítios de produção e acumulação de óleos essenciais nessa espécie. Nos outros tipos de tricomas (capitados), 
Figura 1 - Eletromicrografia de varredura da superfície foliar de L. sidoides
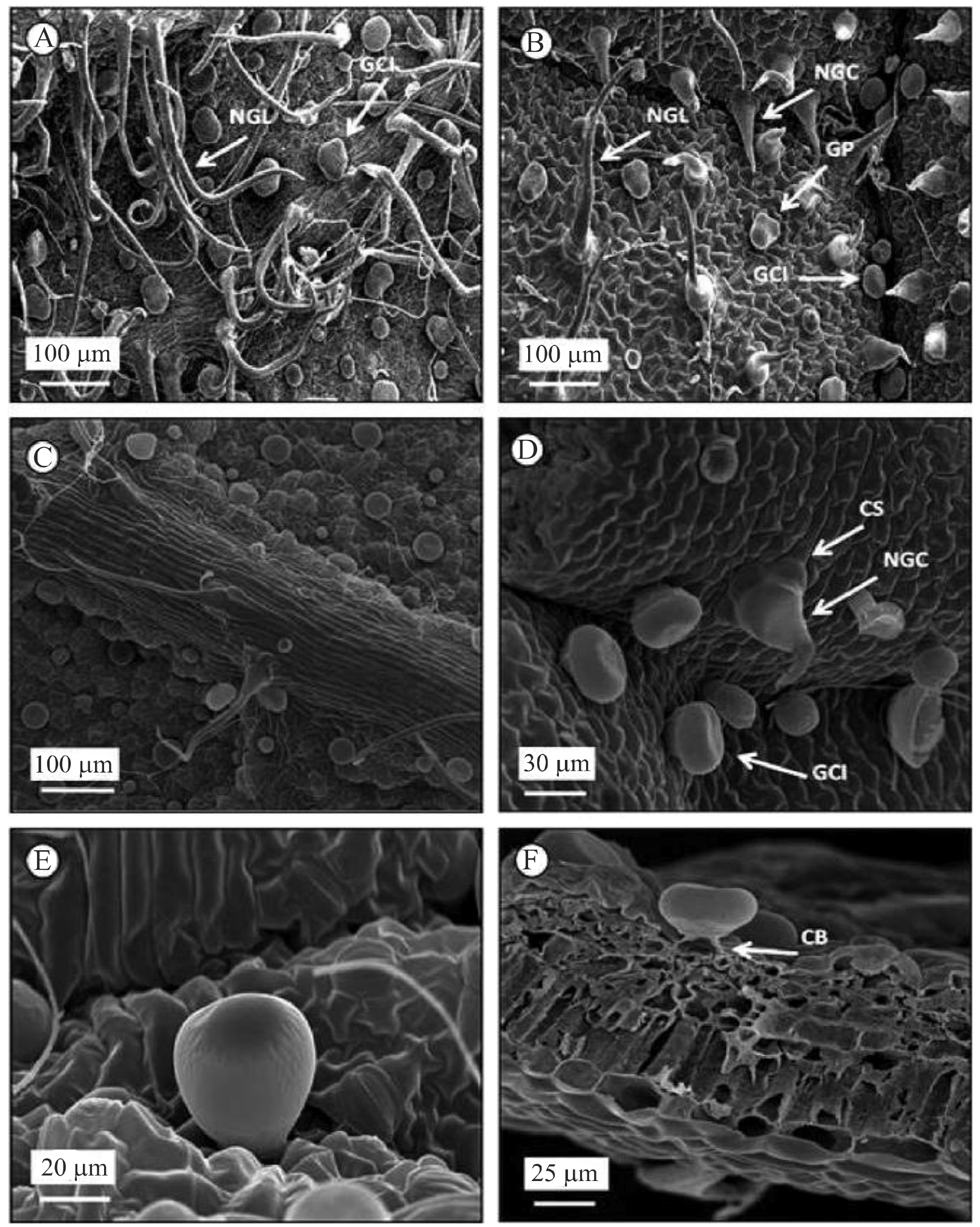

A - Tricomas glandulares capitados tipo I (GCI) e tricomas não glandulares tectores longos (NGL) presentes na superfície abaxial. B - Tricomas não glandulares tectores longos (NGL), tricomas não glandulares cônicos (NGC), tricomas glandulares capitados tipo I (GCI) e tricomas glandulares peltados (GP) presentes na superfície adaxial. C - Tricomas não glandulares e glandulares presentes na nervura central na face abaxial. D - Tricoma não glandular cônico (NGC) com células subsidiárias (CS) na base e tricomas glandulares capitados tipo I (GCI). E tricoma capitado tipo I. F - Seção transversal, com detalhe de uma célula basal (CB) de um tricoma glandular capitado tipo I 
Figura 2 - Secções transversais das folhas de L. sidoides
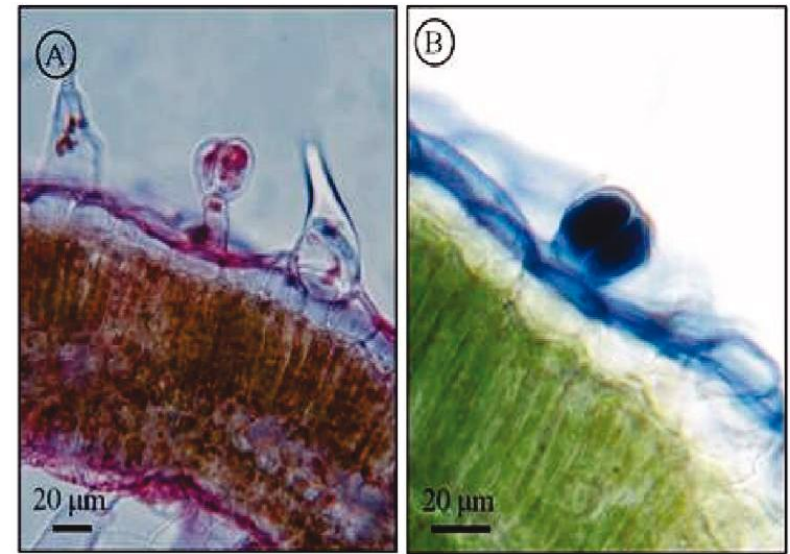

A - tricoma capitado tipo I e tricoma não glandular presentes na superfície adaxial, evidenciando a presença de substâncias lipofílicas presentes no interior do tricoma. B - Tricoma capitado tipo I na superfície adaxial, confirmando a presença de terpenos (óleo essencial)

foram encontradas secreções mais complexas, contendo substâncias hidrofílicas e lipofílicas, havendo também a presença de óleo essencial, porém em menores teores.

A Figura 3 demonstra, por diferentes equações de regressão, os resultados da atividade antibacteriana do óleo essencial de $L$. sidoides e do carvacrol sobre a progressão de formação de halos de inibição das bactérias Clavibacter michiganensis subsp. Michiganensis, Xanthomonas vesicatoria e Pseudomonas syringae pv. Tomato submetidas aos diferentes tratamentos. O 1,8cineol nas concentrações avaliadas, não apresentou inibição sobre o crescimento das fitobactérias estudadas.

Houve diferença significativa para as diferentes concentrações de óleo essencial e do carvacrol sobre a formação dos halos de inibição do crescimento dos microrganismos Clavibacter michiganensis e Xanthomonas vesicatoria. De acordo com as análises estatísticas de regressão, a formação dos halos de inibição do crescimento destes microrganismos diante das concentrações dos compostos estudados obedeceram a uma equação de segundo grau, havendo um aumento acentuado nos diâmetros dos halos de inibição do crescimento nas menores concentrações e uma estabilização destes valores nas maiores concentrações. Por outro lado, a análise de regressão para a formação dos halos de inibição do crescimento de Pseudomonas syringae, demonstrou que a formação dos mesmos segue uma equação logarítmica. Porém, esta análise foi significativa apenas para o efeito das concentrações do óleo essencial, para o carvacrol, apesar de ter apresentado formação do halo de inibição do crescimento, não houve variação do tamanho deste com o aumento das concentrações.
Figura 3 - Diâmetros dos halos de inibição do crescimento in vitro de Clavibacter michiganensis subsp. Michiganensis (Pmm) (A), Xanthomonas vesicatoria (Xv) (B) $\mathrm{e}$ Pseudomonas syringae pv. tomato (Pst) (C) provocados pelo óleo essencial e o carvacrol
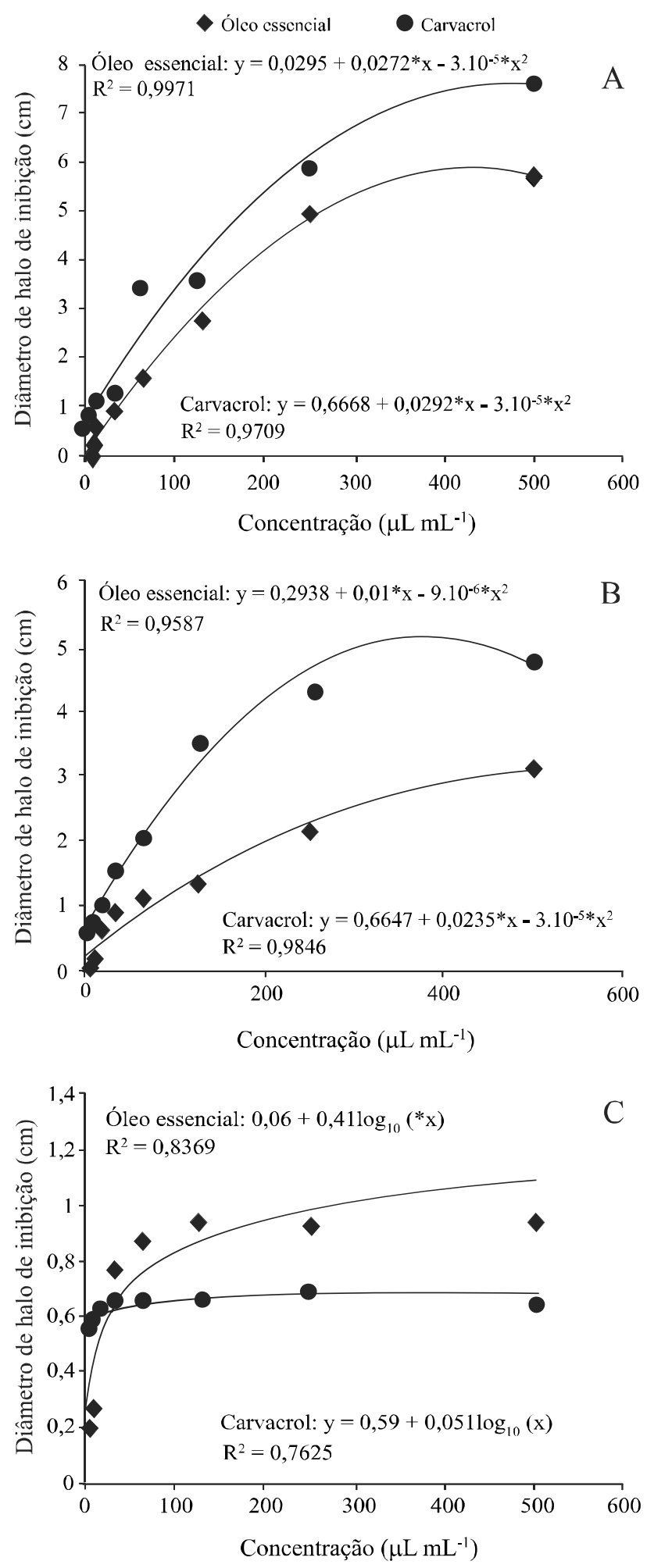
Diante dos resultados observa-se que o microrganismo mais sensível aos compostos estudados foi a Clavibacter michiganensis, uma vez que, sobre o seu crescimento houve a formação dos maiores halos inibição, sendo igual a 7,6 e 5,67 cm de diâmetro perante a concentração de $500 \mu \mathrm{g} \mathrm{mL}^{-1}$ do carvacrol e do óleo essencial, respectivamente. Observa-se que o efeito do carvacrol é maior que o do óleo essencial sobre a formação dos halos de inibição do crescimento de Clavibacter michiganensis e Xanthomonas vesicatoria. Desta forma, pode-se inferir que dentre os constituintes do óleo essencial, o carvacrol é um dos compostos responsável pela atividade do mesmo. Por outro lado, sobre a formação dos halos de inibição do crescimento de Pseudomonas syringae, observa-se que a atividade do óleo essencial é maior que a apresentada pelo carvacrol.

Estes resultados encontram-se de acordo com aqueles apresentados por Andrade et al. (2012), que avaliando a atividade antibacteriana dos óleos essenciais de Cinnamomum zeylanicum, Cymbopogon nardus e Zingiber officinale sobre diversas bactérias contaminadoras de alimentos, verificaram o efeito inibitório destes sobre bactérias Gram-positivas e Gram-negativas.

Vários trabalhos relatam que bactérias Grampositivas são mais susceptíveis à atividade de óleos essenciais que bactérias Gram-negativas. Lima et al. (2012), estudando a atividade antibacteriana dos óleos essenciais de Myristica fragrans e Salvia microphylla sobre diversas bactérias, observaram maiores atividades dos mesmos sobre as bactérias Gram-positivas. Tepe et al. (2005), avaliando a atividade antibacteriana do óleo essencial de Salvia tomentosa, observaram a ausência de atividade desse óleo sobre os microrganismos Gramnegativos estudados, Escherichia coli, Proteus mirabilis e Pseudomonas aeroginosa.

Fontenelle et al. (2007) já haviam demonstrado atividade antimicrobiana do óleo essencial de $L$. sidoides sobre dez cepas de Malassezia canis, cinco de Candida albicans e três de Candida tropicalis, revelando sua potencialidade como agente no controle microbiano. A alta atividade apresentada pelo óleo de L. sidoides deve-se à presença do carvacrol em sua constituição. Em muitos trabalhos relatam-se as atividades antimicrobianas desse composto e de seu isômero timol. A não seletividade apresentada por esse composto diante das bactérias Gramnegativas e Gram-positivas corroboram com trabalhos de Bozin et al. (2006), que avaliaram as atividades antimicrobianas dos óleos essenciais de Origanum vulgare, Thymus vulgaris e Ocimun vulgare sobre cinco cepas de bactérias Gram-positivas e oito de bactérias Gramnegativas, como Pseudomonas aeroginosa, Escherichia coli, entre outras. Apesar de em muitos estudos demonstrarse a atividade antibacteriana de muitos óleos essenciais, pouco se sabe a respeito do seu mecanismo de ação e de seus compostos isolados. Vários trabalhos relatam uma possível interação com a membrana celular. De acordo com Sikkema, Bont e Poolman (1995), a permeabilidade de membranas celulares é dependente da hidrofobicidade dos solutos que estão em sua volta e da sua composição. Segundo Lambert et al. (2001), o coeficiente de partição do óleo essencial na membrana celular é de fundamental importância para sua efetividade, fato que está relacionado às variações nas atividades dos óleos essenciais frente a diferentes bactérias, principalmente no que diz respeito às bactérias com diferentes tipos de Gram.

\section{CONCLUSÕES}

1.O óleo essencial de L. sidoides apresentou como constituintes majoritários o 1,8-cineol $(22,63 \pm 0,40 \%)$ e o carvacrol $(26,44 \pm 0,65 \%)$;

2.As superfícies foliares de $L$. sidoides apresentaram a presença de tricomas glandulares e não glandulares. Os compostos terpênicos ou parte destes, constituintes do óleo essencial desta espécie encontram-se armazenado nos tricomas glandulares;

3.O óleo essencial de L. sidoides e o carvacrol, seu constituinte majoritário, apresentaram atividades antibacterianas sobre bactérias fitopatogênicas Grampositivas e Gram-negativas.

\section{AGRADECIMENTOS}

Ao Conselho Nacional de Desenvolvimento Científico e Tecnológico (CNPq), à Fundação de Amparo à Pesquisa de Minas Gerais (FAPEMIG) pela concessão de bolsa de estudos e pelo suporte financeiro; e ao Laboratório de Microscopia Eletrônica e Análises Ultra-estrutural da UFLA, pela realização das análises de MEV.

\section{REFERÊNCIAS}

ADAMS, R. P. Identification of essential oil components by gas chromatography/mass spectrometry. 4. ed. Carol Stream: Allured, 2007. $800 \mathrm{p}$.

ANDRADE, M. A. et al. Óleos essenciais de Cymbopogon nardus, Cinnamomum zeylanicum e Zingiber officinale: composição, atividade antioxidante e antibacteriana. Revista Ciência Agronômica, v. 43, n. 2, p. 399-408, 2012.

BAKKALI, F. et al. Biological effects of essential oils: a review. Food and Chemical Toxicology, v. 46, n. 2, p. 446-475, 2008. 
BARROS, E. M. C. et al. Variabilidade sazonal e biossíntese de terpenóides presentes no óleo essencial de Lippia Alba (Mill) N. E. Brown (verbenaceae). Química Nova, v. 32, n. 4, p. 861-867, 2009.

BERTINI, L. M. et al. Perfil de sensibilidade de bactérias frente a óleos essenciais de algumas plantas do Nordeste do Brasil. Infarma, v. 17, n. 3/4, p. 80-83, 2005.

BOTELHO, M. A. et al. Antimicrobial activity of the essential oil from Lippia sidoides, carvacrol and thymol against oral pathogens. Brazilian Journal of Medicinal and Biological Research, v. 40, n. 3, p. 349-356, 2007.

BOZIN, B. et al. Characterization of the volatile composition of essential oils of some Lamiaceae spices and the antimicrobial and antioxidant activities of the entire oils. Journal of Agricultural and Food Chemistry, v. 54, n. 5, p. $1822-1828,2006$.

CAVALCANTI, S. C. H. et al. Composition and acaricidal activity of Lippia sidoides essential oil against two-spotted spider mite (Tetranychus urticae Koch). Bioresource Technology, v. 101, n. 2, p. 829-832, 2010.

CAVALCANTI, E. S. B. et al. Larvicidal activity of essential oils from brazilian plants against Aedes aegypti L. Memórias do Instituto Oswaldo Cruz, v. 99, n. 5, p. 541-544, 2004.

COMBRICK, S. et al. Morphology and histochemistry of glandular trichomes of Lippia scaberrima (Verbenaceae). Annals of Botany, v. 99, n. 6, p. 1111-1119, 2007.

FERREIRA, D. F. análises estatísticas por meio do sisvar para windows versão 4.0. In: REUNIÃO ANUAL DA REGIÃO BRASILEIRA DA SOCIEDADE INTERNACIONAL DE BIOMETRIA, 45., 2000, São Carlos. Anais... São Carlos: UFSCar, 2000. p. 255-258.

FONTENELLE, R. O. S. et al. Chemical composition, toxicological aspects and antifungal activity of essential oil from Lippia sidoides Cham. Journal of Antimicrobial Chemotherapy, v. 59, n. 5, p. 934-940, 2007.

GOBBO-NETO, L.; LOPES, N. P. Plantas medicinais: fatores de influência no conteúdo de metabólitos secundários. Química Nova, v. 30, n. 2, p. 374-381, 2007.

KIMATI, H. et al. Manual de fitolpatologia: doenças das plantas cultivadas. 4. ed. São Paulo: Agronômica Ceres, 2005. 663 p. v. 2.

LABARRIOS, L. A. A. et al. Detección de Clavibacter michiganensis subsp. Nebraskensis (Schuster, Hoff, Mandel y Lazar) Vidaver y Mandel, usando La reacción em cadena de La olimerasa. Revista Mexicana de Fitopatologia, v. 22, n. 2, p. 239-245, 2004.

LAMBERT, R. J. W. et al. Estudy of the minimum inhibitory concentration and mode of action of oregano essential oil, thymol and carvacrol. Journal of Applied Microbiology, v. 91, n. 3 , p. $453-462,2001$

LIMA, R. K. et al. Bactericidal and antioxidant activity of essential oil from Myristica fragrans Houtt and Salvia microphylla H. B. K. Journal of the American Oil Chemists' Society, v. 89 n. 3, p. 523-528, 2012.

LIMA, R. K. et al. Chemical composition and fumigant effect of essentialoil of Lippia sidoides Cham. and monoterpenes against Tenebrio molitor (L.) (Coleoptera: Tenebrionidae). Ciência \& Agrotecnologia, v. 35, n. 4, p. 664-671, 2011.

LUCAS, G. C. et al. Antibacterial activity of essential oils on Xanthomonas vesicatoria and control of bacterial spot in tomato. Pesquisa Agropecuária Brasileira, v. 47, n. 3, p. 351-359, 2012.

MAGGI, F. et al. Histochemical localization of secretion and composition of the essential oil in Melittis melissophyllum L. subsp. Melissophyllun from Central Italy. Flavour and Fragrance Journal, v. 25, n. 2, p. 63-70, 2010.

NASCIMENTO-SILVA, O.; PAIVA, J. G. A. Estudos morfológicos e anatômicos em folhas adultas de Spondias tuberosa Arruda (Anacardiaceae Lindley). Boletín Latinoamericano y del Caribe de Plantas Medicinales y Aromáticas, v. 6, n. 2, p. 36-43, 2007.

PIMENTEL, F. A. et al. A convenient method for the determination of moisture in aromatic plants. Química Nova, v. 29, n. 2, p. 373-375, 2006.

SILVA, J. R. C. et al. Bactérias endofíticas no controle e inibição In vitro de Pseudomonas syringae pv tomato, agente da pinta bacteriana do tomateiro. Ciência \& Agrotecnologia, v. 32, n. 4, p. 1062-1072, 2008.

SIKKEMA, J.; BONT, J. A. M.; POOLMAN, B. Mechanisms of membrane toxicity of hydrocarbons. Microbiology Reviews, v. 59, n. 2, p. 201-222, 1995.

SVOBODA, K. P.; GREENAWAY, R. I. Investigation of volatile oil glands of Satureja hortensis L. (summer savory) and phytochemical comparison of different varieties. The International Journal of Aromatherapy, v. 13, n. 4, p. 196202, 2003.

TEPE, B. et al. Antimicrobial and antioxidant activities of the essential oil and various extracts of Salvia tomentosa Miller (Lamiaceae). Food Chemistry, v. 90, n. 3, p. 333340, 2005. 